\title{
Comparative Study of Conventional and Water Circulating-Heat Sink Cooling Base Thermoelectric Generator System for Optimum Solar Thermal Waste Heat Recovery
}

\author{
${ }^{* 1}$ YUSUF, A; ${ }^{2}$ ALI, MH \\ ${ }^{* 1}$ Department of Physics, Kaduna State University, Kaduna State, Nigeria \\ ${ }^{2}$ Department of Physics, Bayero University Kano, Kano State, Nigeria, Email: alim@buk.edu.ng \\ *Corresponding Author Email: yusuf.aliyu@kasu.edu.ng
}

\begin{abstract}
A novel technique for waste heat recovery in solar thermal power generation is investigated through experimentation and systematically presented. Power generation using Thermoelectric Generator (TEG) is a promising technique in waste heat recovery application. In this topology, TEG array is directly attached to the back of the solar Photovoltaic panel (model AP-AM15) to receive the transmitted heat at the back of the PV panel as waste heat. More so, a circulating water-heat sink is attached to the TEG cold side to improve the temperature gradient. Base on Seebeck effect, the TEG directly converts the temperature difference into electricity. The experimental result shows that efficiency between the range of $2.1 \%$ and $4.7 \%$ for the conventional cooling system while the output power approximately ranges between $0.05 \mathrm{~W}$ and $0.47 \mathrm{~W}$, the circulating water-heat sink technique has efficiency ranging between $2.9 \%$ and $10.3 \%$ with output power between the range of $0.10 \mathrm{~W}$ and $2.2 \mathrm{~W}$. The daily average increase in efficiency was found to be $263.76 \%$. This shows that the daily average power is improved by a factor of 2.6376 with the water circulating water-heat sink technique. This is an indication of waste heat recovery from the solar thermal power generation.
\end{abstract}

DOI: https://dx.doi.org/10.4314/jasem.v25i4.3

Copyright: Copyright (C) 2021 Yusuf and Ali. This is an open access article distributed under the Creative Commons Attribution License (CCL), which permits unrestricted use, distribution, and reproduction in any medium, provided the original work is properly cited.

Dates: Received: 03 February 2021; Revised: 26 March 2021; Accepted: 05 April 2021

Keywords: Heat-sink, TEG, solar thermal power generation, Waste-Heat Recovery.

Recently, the demand for new energy resources improved the growing concerns due to rising energy prices. The utilization of new alternative sources for the recovery of waste energy gained tremendous attention in the research community (Hoang et al. 2019). The energy recovery from waste sources is considered as the vital key technology targeting to satisfy the approaches of both the efficiency enhancement in energy use and the reduction of pollutants. In recent years, the use of renewable energy and the recycle of waste heat are paid great attention to by several researchers and research institutions. Some technologies for the waste heat recovery have been applied to the reality such as exhaust gas recirculation (Shen, Tian, and Liu 2019), organic Rankine cycle (ORC)-based systems (turbine and boiler) (Wang et al. 2016), and thermoelectric generation (TEG) (Fan et al. 2016; Naphon, Wiriyasart, and Hommalee 2019; Attar, Lee, and Snyder 2020; Du et al. 2015). Among the aforementioned approaches for recovering waste heat, TEG is considered as the promising, possible, and practicable technology harvesting waste heat based on the direct conversion of thermal energy into electrical energy with distinguished characteristics (Wiriyasart et al. 2019). Being highly consistent, low noise, zero emission of environmental pollutant and no operational cost, no moving parts and can directly convert heat into electricity (Al-nimr, Tashtoush, and Hasan 2020). Moreover, the major characteristics advantages of TEGs as compared to ORC-based systems include easy installation and small sizes. In fact, TEGs have been applied to some producing industries, military, transportation sectors, and the life of the human (Wang et al. 2013). Though, some previous research showed the feasibility of TEGs in the waste heat recovery, additional design optimization of such TEG system is needed (Fan et al. 2016; Naphon, Wiriyasart, and Hommalee 2019; Attar, Lee, and Snyder 2020; Du et al. 2015; Wang et al. 2016; Zhang et al. 2015). Mostly, there are two methods of the optimization of TEG systems: One is to optimize the TEG module for the development of new thermoelectric materials and structure design optimization ( $\mathrm{Su}$ et al. 2014); and the other is to enhance the heat transfer from heat source to TEG module hot side and from TEG module cold side to heat sink (e.g. air or coolant) (Abdo, Ookawara, and Ahmed 2019). To gain a comprehensive understanding of the transport phenomena in the TEG systems, some mathematical models have been established by researchers coupling the heat 
source/sink flow and TEG modules. Sornek, Filipowicz, and Rzepka in (Sornek, Filipowicz, and Rzepka 2016) developed a numerical model for TEG modules with a parallel-plate heat exchanger. This model was used to predict the fluid temperatures and the temperatures in the TEG modules. In previous studies, the design optimization of TEG systems mainly focused on conductive systems, convective systems or radiative systems (Huang et al. 2016; Shu et al. 2018; Su et al. 2014).In this study, the effects of cooling design both convective and radiative systems where employed, whereby a coolant liquid (water) is pumped from reservoir by a regulated water pump circulating inside a piped heat sink and passed through a regulated cooling radiator. As this process continues from a free defined temperature, it shows that the TEG cold side temperature can be reduced thereby improving heat transfer. Hence, the output power can be significantly improved by the design optimization of cooling channel. However, the detailed coolant channel design effect and the mass/volume flow rate were largely ignored.

\section{MATERIALS AND METHOD}

TEG System Design: TEG array is an arrangement of TEG modules in series and parallel combinations which are connected thermally in parallel and electrically in series. Each module has large number, $N$ of thermocouple pairs, with an internal resistance of $R_{\mathrm{int}, N}$. A series connected TEG forms a string and parallel arrangement of strings form the array of TEGs with total internal resistance of $R_{T}$ given as (Dalola et al. 2009);

Where $n_{s}$ is the number of TEG in a string, $n_{p}$ is the number of strings in parallel.

The corresponding internal resistance of a TEG with $N$ number of thermocouple pairs is given by (Verma, Kane, and Singh 2016);

$$
\begin{aligned}
& R_{T}=\frac{n_{s}}{n_{p}} R_{\mathrm{int}, N} \\
& R_{\mathrm{int}, N}=N \cdot\left[\frac{2 \rho h}{A}+\frac{2 \rho_{c} l_{c}}{A_{c}}\right]
\end{aligned}
$$

Where $\rho$ is the electrical resistivity of the thermoelectric element, TE, $h$ is the height of the TE leg, $\rho_{c}$ the electrical resistivity of the copper contact, $l_{c}$ the length of the copper contact, $A$ is the cross sectional area of the TE leg, $A_{c}$ cross sectional area of the copper contact, From figure 1, Using Ohm's Law the circuit current, $I_{T E}$, is given as (Carmo et al. 2011);

$$
I_{T E}=\frac{V_{o c, n}}{R_{T}+R_{T E}}
$$

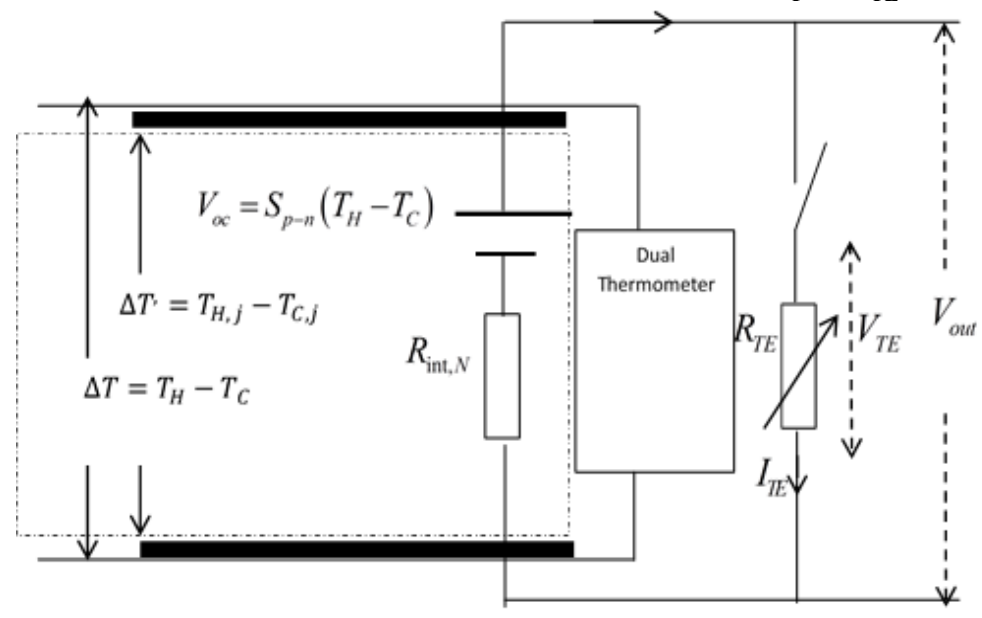

Fig 1: Circuit schematic for measuring the output signals of the thermoelectric generator

$$
\text { And } V_{o c, n}=n_{s} V_{o c}=n_{s} N S_{p-n}\left(T_{H, j}-T_{C, j}\right)
$$

Where $V_{o c, n}$ is the open circuit voltage of the TEG, $V_{o c}$ is the open circuit voltage of the thermocouple single pair, $R_{T E}$ is the load resistance across the TEG and $S_{p-n}$ is the Seebeck coefficient of a thermoelectric p-type and n-type single pair. $T_{H, j}$ and 
$T_{C, j}$ are temperature of the hot and the cold junctions respectively (Carmo et al. 2011).

Electrical Potential, $V_{T E}$ at the output circuit across the load resistor $R_{T E}$ is given by (Dalola et al. 2009).

$$
V_{T E}=n_{s} S_{p-n} N\left(T_{H, j}-T_{C, j}\right) \cdot \frac{R_{T E}}{R_{T}+R_{T E}}
$$

The electric power generated at the output, $P_{T E}$, by the thermoelectric generator array can be found using equation (3), (4) and (5)

$$
P_{T E}=I_{T E} V_{T E}=R_{T E} \cdot\left[\frac{n_{s} S_{p-n} N\left(T_{H, j}-T_{C, j}\right)}{\left(R_{T}+R_{T E}\right)}\right]^{2}
$$

For maximum output power simulation at matched load condition $\left(R_{T E}=R_{T}\right)$, the maximum Power, $P_{T E, \max }$ can be obtained from equation (6) using equation (1) and (2) as (Carmo et al. 2011);

$$
P_{T E, \max }=\frac{n_{s} n_{p} N \cdot S_{p-n}^{2}\left(\Delta T^{\prime}\right)^{2}}{8 \cdot\left(\frac{\rho h}{A}+\frac{\rho_{c} l_{c}}{A_{c}}\right)}
$$

Thermal analysis shows that the rates of flow of heat from the waste heat source to the hot junctions through the upper ceramic plates $Q_{H}$, and from the cold junctions to the environment through the lower ceramic plates $Q_{C}$ due to the thermal conduction are respectively given as (Dalola et al. 2009)

$$
\begin{aligned}
& Q_{H}=\left(T_{H}-T_{H, j}\right) K \\
& Q_{C}=\left(T_{C, j}-T_{C}\right) K
\end{aligned}
$$

Where $T_{H}$ and $T_{C}$ are respectively the temperatures of the hot and the cold sides of the substrates, and $K$ is the thermal conductance of the substrates.

This exchange of heat rate at the hot and the cold junctions is the sum of the Peltier effect, the thermal conduction through the couple according to Fourier law and the Joule heat loss due to the flow of current (Dalola et al. 2009; Verma, Kane, and Singh 2016). As a result, $Q_{H}$ and $Q_{C}$ can also be expressed as (Verma, Kane, and Singh 2016)

$$
\begin{aligned}
& Q_{H}=n_{s} N S_{p-n} T_{H, j} I_{T E}+n_{s} n_{p} N k_{\mathrm{int}}\left(T_{H, j}-T_{C, j}\right)-\frac{1}{2} I_{T E}^{2} R_{T} \\
& Q_{C}=n_{s} N S_{p-n} T_{C, j} I_{T E}+n_{s} n_{p} N k_{\mathrm{int}}\left(T_{H, j}-T_{C, j}\right)+\frac{1}{2} I_{T E}^{2} R_{T}
\end{aligned}
$$

where $k_{\text {int }}$ is the internal thermal conductance $\left[W K^{-1}\right]$ of the couple, $K$ is the thermal conductance of the substrates, It can also be seen from equation 8,9, 10 and 11 that,

$$
\frac{\Delta T^{\prime}}{\Delta T} \cong \frac{K}{K+2 n_{s} n_{p} N k_{\mathrm{int}}}=\beta
$$

Where $\Delta T=T_{H}-T_{C}$, is the temperature difference between the hot and the cold substrates and $\beta$ is the ratio between the temperature gradients between the substrate and temperature gradient between the TE elements (Manikandan and Kaushik 2015).

A useful parameter for the performance assessment of a TEG is the power factor, $P F$ and efficiency, $\eta$ (Montecucco, Siviter, and Knox 2015). Montecucco et al. in (Montecucco, Siviter, and Knox 2015) defined $P F$ as the power in matched-load conditions per unit squared temperature gradient per unit module area $A_{m}$ . According to this definition and considering equation 7 and equation 12, the power factor of the array can be described by the following equation (Montecucco, Siviter, and Knox 2015):

$$
\begin{gathered}
P F=\frac{P_{T E, \max }}{(\Delta T)^{2} A_{m}}=\frac{n_{s} n_{p} N S_{p-n}^{2} \beta^{2}}{8 A_{m}\left(\frac{\rho h}{A}+\frac{\rho_{C} l_{C}}{A_{C}}\right)} \\
\text { Efficiency, } \eta_{T E}=\frac{\text { Output Power }}{\text { Input power }}=\frac{P_{T E}}{Q_{H}}
\end{gathered}
$$

Using equation 6,8 and 11, the efficiency can be welldefined as (Montecucco, Siviter, and Knox 2015);

$$
\eta_{T E}=\frac{P_{T E}}{Q_{H}}=\frac{R_{T E} \cdot\left[\frac{n_{s} n_{p} N \cdot S_{p-n}(\Delta T) \beta}{\left(R_{T}+R_{T E}\right)}\right]^{2}}{n_{s} N S_{p-n} T_{H, j} I_{T E}+n_{s} n_{p} N k_{\mathrm{int}}\left(T_{H, j}-T_{C, j}\right)-\frac{1}{2} I_{T E}^{2} R_{T}}
$$

Where $k_{\text {int }}$ is the thermal conductance given as (Montecucco, Siviter, and Knox 2015); 


$$
k_{\text {int }}=\frac{2 \lambda A}{h}
$$

And $\lambda$ is the thermal conductivity of the TE material $[W /(K m)]$ (Dalola et al. 2009) .

At matched load condition, the maximum efficiency can be found as (Dalola et al. 2009).

$$
\eta_{T E, \max }=\frac{n_{p}^{2} \Delta T \beta}{2 T_{H, j}+\frac{16 \lambda A}{S_{p-n}^{2} h}\left(\frac{\rho h}{A}+\frac{\rho_{c} l_{c}}{A_{c}}\right)-\frac{\Delta T \beta}{2}}
$$

The daily average increase in efficiency $\eta_{\text {avg }}$ can then be estimated as (Motahhir et al. 2019);

$$
\eta_{\text {avg }}=\frac{\sum\left(P_{C, s y s}-P_{N C, s y s}\right)}{\sum P_{N C, s y s}} \times 100 \%
$$

Where $P_{C, s y s}$ is the daily average output power of the TEG with cooling system and $P_{N C \text {,sys }}$ is the daily average output power of the TEG when there is no cooling system (Motahhir et al. 2019).

Method: The experimental set up is as shown on plate 1 , plate 2 shows the developed series and parallel arrangement of the TEG. The schematic on figure 2 was used to explain the experimental procedure. The Rheostat was adjusted to obtain the current-voltage characteristics of the TEG model (SP1848-SA27145), using digital multimeters (SD9205A).

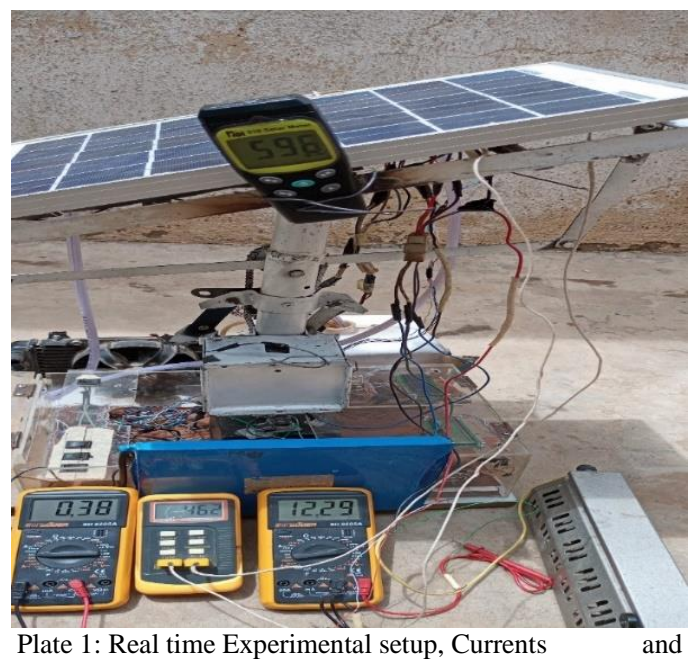

$$
\text { Voltages measurements }
$$

The amount of irradiance and temperature profile of the PV panel, TEG and the ambient were taken using solar radiation meter (Model pi 510) and dual digital thermometer (model 6802II TWOK-TYPE) respectively. The experiment was conducted at different time of the day under natural convection when there is no cooling of the TEG. When the cooling was introduced similar electrical parameters were also recorded. This procedure was followed in order to get the load current, $I_{L}$ and voltage, $V_{L}$ characteristics with the cooling and without cooling of the TEG cold side, it also allowed to develop $P_{L^{-}} V_{L}$ and $P_{L^{-}} I_{L}$ characteristics of the TEG (Ali and Yusuf 2017). The positions of the maximum power point were located on the plots in MATLAB environment.

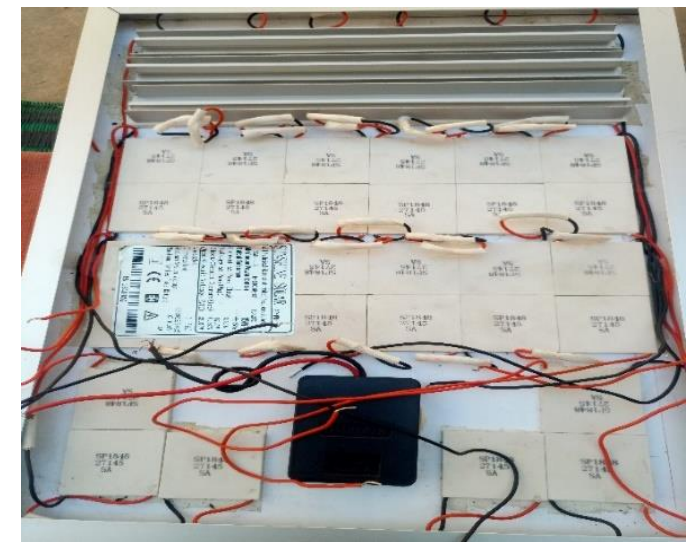

Plate 2: Series and parallel arrangement of TEGs at the back of the

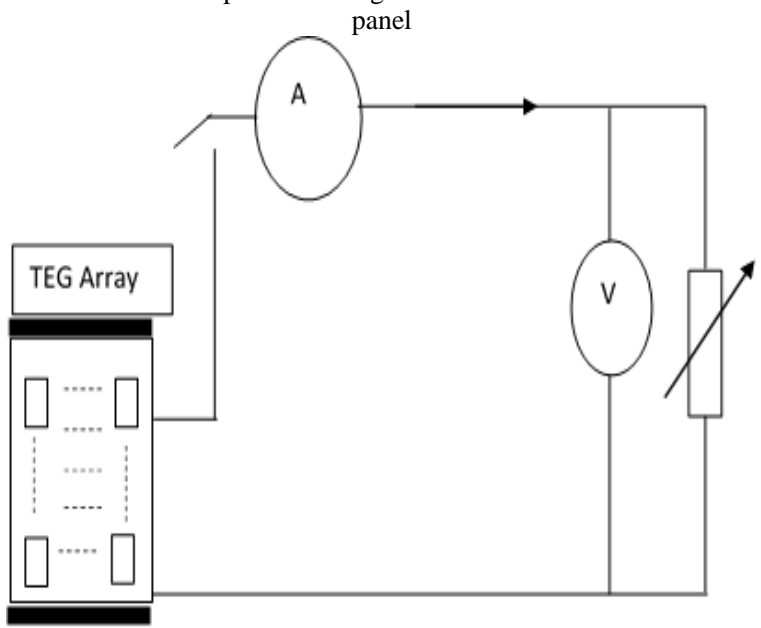

Figure 2: Experimental schematics for measuring the Currents and Voltages

\section{RESULTS AND DISCUSSION}

The characteristics behaviors of both the I-V and P-V characteristics curves for both the convectional and the cooling systems models obtained and the known parameters from the datasheet as well as the unknown parameters obtained from MATLAB simulation for the TEG model (SP1848-SA27145) were recorded by 
employing the method in (Ali and Yusuf 2017). The measured data were plotted in figure 1 and 2 , the measurement was done hourly from $8 \mathrm{am}$ to $5 \mathrm{pm}$ for both the conventional and the cooling system Adopted on $16^{\text {th }}$ February 2020 . The position of the maximum power point MPP on the plots where located and recorded. Table 1 presents the important output parameters obtained from the I-V characteristics of the TEG on $26^{\text {th }}$ February 2020 using the conventional cooling method, and table 2 presents the same parameters extracted when the cooling system was introduced.

Table 1: Electrical characterization of TEG without cooling fluid dated $16^{\text {th }}$ February, 2020

\begin{tabular}{|c|c|c|c|c|c|c|c|c|c|c|}
\hline Time/H & $\mathrm{Tl} /{ }^{\circ} \mathrm{C}$ & $\mathrm{T} 2 /{ }^{\circ} \mathrm{C}$ & $\mathrm{DT} /{ }^{\circ} \mathrm{C}$ & $\mathrm{Ise} / \mathrm{A}$ & Voc/V & $\operatorname{Imp} / \mathrm{A}$ & $\mathrm{Vmp} / \mathrm{V}$ & Pmp/W & $\mathrm{Pin} / \mathrm{W}$ & Efficiency $/ \%$ \\
\hline 8 & 30.1 & 33 & 2.9 & 0.306 & 0.768 & 0.153 & 0.383 & 0.059 & 2.7236 & 2.1560 \\
\hline 9 & 34.6 & 37.9 & 3.3 & 0.348 & 0.874 & 0.174 & 0.436 & 0.076 & 3.3338 & 2.2807 \\
\hline 10 & 37.6 & 41.2 & 3.6 & 0.380 & 0.953 & 0.190 & 0.476 & 0.090 & 3.7767 & 2.3959 \\
\hline 11 & 40.3 & 46.2 & 5.9 & 0.622 & 1.563 & 0.312 & 0.779 & 0.243 & 6.5619 & 3.7039 \\
\hline 12 & 46.0 & 52.7 & 6.7 & 0.707 & 1.774 & 0.354 & 0.885 & 0.313 & 8.0691 & 3.8843 \\
\hline 13 & 52.7 & 60.1 & 7.4 & 0.780 & 1.960 & 0.391 & 0.978 & 0.382 & 9.6499 & 3.9621 \\
\hline 14 & 46.2 & 54.4 & 8.2 & 0.865 & 2.172 & 0.433 & 1.083 & 0.469 & 9.9991 & 4.6952 \\
\hline 15 & 45.0 & 51.1 & 6.1 & 0.643 & 1.616 & 0.322 & 0.806 & 0.260 & 7.2258 & 3.5955 \\
\hline 16 & 40.8 & 45.8 & 5.0 & 0.527 & 1.324 & 0.264 & 0.661 & 0.175 & 5.5705 & 3.1335 \\
\hline 17 & 37.1 & 41.1 & 4.0 & 0.422 & 1.059 & 0.211 & 0.528 & 0.112 & 4.1990 & 2.6605 \\
\hline
\end{tabular}

Table 2: Electrical characterization of TEG with cooling fluid dated $16^{\text {th }}$ February, 2020

\begin{tabular}{|c|c|c|c|c|c|c|c|c|c|c|}
\hline Time/H & $\mathrm{Tl} /{ }^{\circ} \mathrm{C}$ & $\mathrm{T} 2 /{ }^{\circ} \mathrm{C}$ & DT $/{ }^{\circ} \mathrm{C}$ & Isc/A & $\mathrm{Voc} / \mathrm{V}$ & $\operatorname{Imp} / \mathrm{A}$ & $\mathrm{Vmp} / \mathrm{V}$ & $\mathrm{Pmp} / \mathrm{W}$ & $\mathrm{Pin} / \mathrm{W}$ & Efficiency $/ \%$ \\
\hline 8 & 29.2 & 33.1 & 3.9 & 0.411 & 1.033 & 0.206 & 0.515 & 0.106 & 3.661 & 2.901 \\
\hline 9 & 31.5 & 37.9 & 6.4 & 0.675 & 1.695 & 0.338 & 0.846 & 0.286 & 6.382 & 4.481 \\
\hline 10 & 32.4 & 37.5 & 5.1 & 0.538 & 1.351 & 0.270 & 0.674 & 0.182 & 5.080 & 3.575 \\
\hline 11 & 34.5 & 42.9 & 8.4 & 0.886 & 2.225 & 0.444 & 1.110 & 0.493 & 8.905 & 5.532 \\
\hline 12 & 35.9 & 49.8 & 13.9 & 1.466 & 3.681 & 0.735 & 1.836 & 1.349 & 15.810 & 8.533 \\
\hline 13 & 37.1 & 54.6 & 17.5 & 1.845 & 4.635 & 0.925 & 2.312 & 2.138 & 20.860 & 10.251 \\
\hline 14 & 36.9 & 52.8 & 15.9 & 1.677 & 4.211 & 0.840 & 2.101 & 1.765 & 18.641 & 9.469 \\
\hline 15 & 38.5 & 48.7 & 10.2 & 1.076 & 2.701 & 0.539 & 1.348 & 0.726 & 11.577 & 6.275 \\
\hline 16 & 33.9 & 42.8 & 8.9 & 0.939 & 2.357 & 0.470 & 1.176 & 0.553 & 9.407 & 5.879 \\
\hline 17 & 32.8 & 39.7 & 6.9 & 0.728 & 1.827 & 0.365 & 0.912 & 0.332 & 7.042 & 4.720 \\
\hline
\end{tabular}
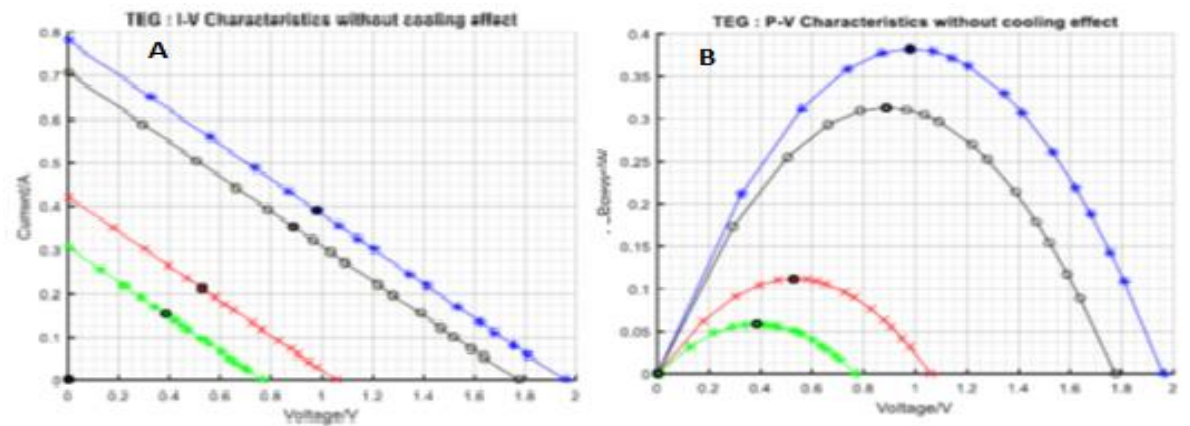

Fig 3: Electrical Characteristics of TEG arrays without cooling (a) I-V Characteristics (b) P-V Characteristics
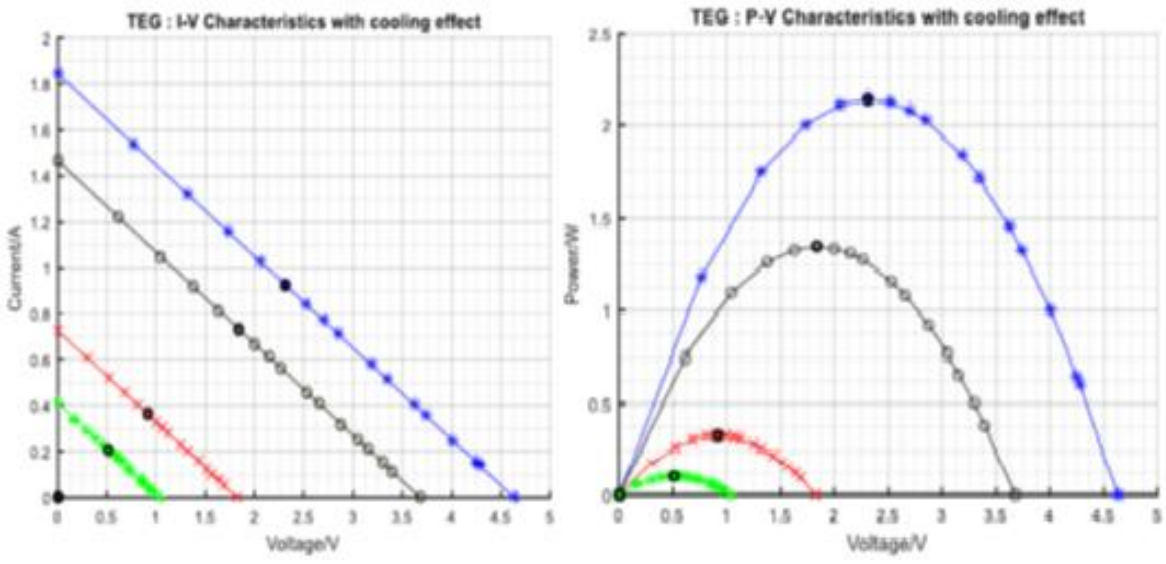

Fig 4 Electrical Characteristics of TEG arrays with cooling (a) I-V Characteristics (b) P-V Characteristics 

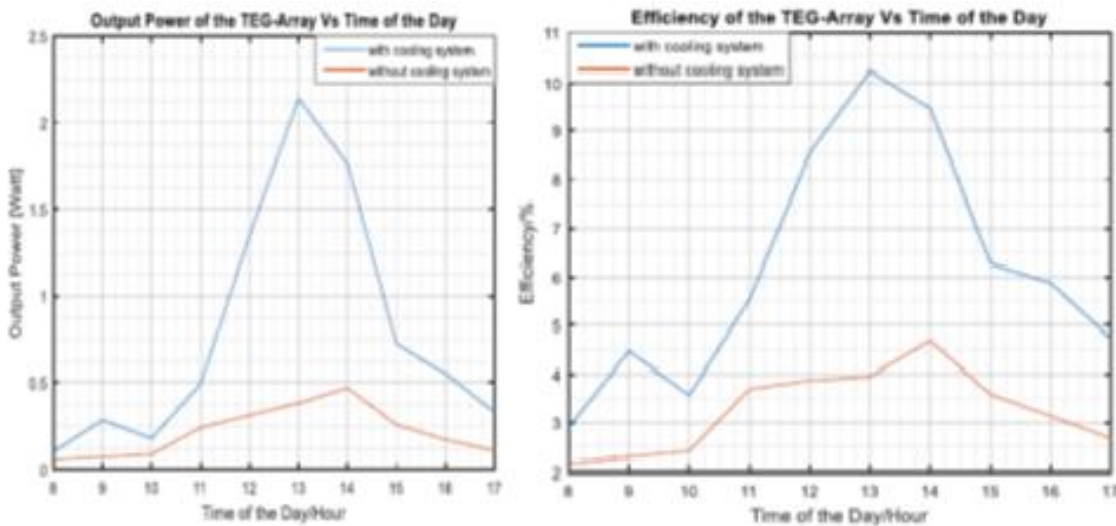

Fig 5: (a) Output power of the TEG with and without cooling system Vs time of the day (b) Efficiency of the TEG with and without cooling system Vs time of the day

The daily average efficiency of the TEG with the conventional cooling was found as;

$$
\frac{0.218}{6.111} x 100 \%=3.568 \%
$$

The daily average efficiency of the TEG with cooling technique was found as;

$$
\frac{0.793}{10.737} \times 100 \%=7.386 \%
$$

The daily average increase in efficiency of the TEG with cooling system as compared to TEG with the conventual cooling system was found as;

$$
\frac{0.793-0.218}{0.218} \times 100 \%=263.76 \%
$$

Figure 3 and 4 depicted the I-V and P-V characteristics plots for the TEG array from which the maximum power point MPP were located by simulation in MATLAB environment. Figure 5 and 6 depicted the plots of output power and efficiency variation with respect to time of the day. The maximum power was seen to be around the noon from $12 \mathrm{pm}$ up to $2 \mathrm{pm}$ of figure 5 . Similarly, the maximum efficiency was seen to be around the same time interval, which is the period were infrared radiation from the sun seems to be maximum in a day. The daily average efficiencies obtained from the conventional and cooling method adopted were $3.568 \%$ and $7.386 \%$ respectively. The daily average increase in efficiency of this cooling technique as compared to the conventional one is $263.76 \%$. This shows that the daily average power is improved by a factor of 2.64 . This is an indication that cooling the TEG with a coolant (water in this case) increases the temperature gradient of TEG, thus, higher amount of power can be recovered and hence improved the performance of the TEG for waste heat recovery application.

Conclusion: Characteristics behavior of both the TEG system with convectional cooling and water circulating-heat sink cooling techniques were studied in this work. The MPPs were located to investigate the maximum power for both the systems. The daily maximum power for both the systems were found to be around the midday. The proposed water circulatingheat sink technique has a higher output power and efficiency than that of the conventional cooling system. This indicates that the proposed method can enhance the TEG power generation system, hence, the performance of TEG in thermal waste heat recovery application can be improved.

\section{REFERENCES}

Abdo, Ahmed, Shinichi Ookawara, and Mahmoud Ahmed. 2019. Performance Evaluation of a New Design of Concentrator Photovoltaic and Solar Thermoelectric Generator Hybrid System.Energy Con. Manage. 195 (April): 1382-1401.

Al-nimr, Ahmad, Bourhan Tashtoush, and Alabas Hasan. 2020. A Novel Hybrid Solar Ejector Cooling System with Thermoelectric Generators. Energy 198: 117318 .

Ali, M H, and A Yusuf. 2017. Comparative Study of Parameter Extraction and Estimation Based on The PV Module Outdoor Performance Using Differential Evolution, Lambert $\mathrm{W}$ Function and Iterative Technique J. Nig. Inst. Phy. 27 (2).

Attar, Alaa, Hosung Lee, and G Jeffrey Snyder. 2020. Optimum Load Resistance for a Thermoelectric Generator SystemEnergy Con. Manag. 226113490.

Carmo, J. P., Joaquim Antunes, M. F. Silva, J. F. Ribeiro, L. M. Goncalves, and J. H. Correia. 2011. 
"Characterization of Thermoelectric Generators by Measuring the Load-Dependence Behavior." Measurement: J. Inter. Measure. Confed. 44 (10): 2194-99.

Dalola, Simone, Marco Ferrari, Vittorio Ferrari, Michele Guizzetti, Daniele Marioli, and Andrea Taroni. 2009. "Characterization of Thermoelectric Modules for Powering Autonomous Sensors." IEEE Transact. Instrument. Measure. 58 (1): 99-107.

Du, Qing, Hai Diao, Zhiqiang Niu, Guobin Zhang, Gequn Shu, and Kui Jiao. 2015. "Effect of Cooling Design on the Characteristics and Performance of Thermoelectric Generator Used for Internal Combustion Engine." Energy Conv. Manage. 101: 918.

Fan, Linhao, Guobin Zhang, Renfang Wang, and Kui Jiao. 2016. "A Comprehensive and Time-Efficient Model for Determination of Thermoelectric Generator Length and Cross-Section Area." Energy Conv. Manage. 122: 85-94.

Hoang, Anh Tuan, Xuan Phuong Nguyen, Anh Tuan Le, Minh Tuan Pham, Trung Huan Hoang, Abdel Rahman M Said Al-tawaha, and Surfa Yondri. 2019. "Environmental Effects Power Generation Characteristics of a Thermoelectric Modules-Based Power Generator Assisted by Fishbone-Shaped Fins : Part II - Effects of Cooling Water Parameters Based Power Generator Assisted by Fishbone-Shaped Fins : Part II - Ef." Energy Sources, Part A: Recovery, Utilization, and Environmental Effects 0 (0): 1-13

Huang, Gia-yeh, Cheng-ting Hsu, Chun-jen Fang, and Da-jeng Yao. 2016. "Optimization of a Waste Heat Recovery System with Thermoelectric Generators by Three-Dimensional Thermal Resistance Analysis." Energy Con. Manage. 126: 581-94.

Manikandan, S, and S C Kaushik. 2015. "Thermodynamic Studies and Maximum Power Point Tracking in Thermoelectric Generator Thermoelectric Cooler Combined System." CRYOGENICS 67: 52-62.

Montecucco, Andrea, Jonathan Siviter, and Andrew R Knox. 2015. "Constant Heat Characterisation and Geometrical Optimisation of Thermoelectric Generators." Appl. Energy 149: 248-58.

Motahhir, Saad, Aboubakr E L Hammoumi, Abdelaziz E L Ghzizal, and Aziz Derouich. 2019. "Open Hardware / Software Test Bench for Solar Tracker with Virtual Instrumentation." Sustain. Energy Technol. Assess. 31: 9-16.

Naphon, Paisarn, Songkran Wiriyasart, and Chutichai
Hommalee. 2019. "Experimental and Numerical Study on Thermoelectric Liquid Cooling Module Performance with Different Heat Sink Configurations." Heat and Mass Transfer.

Shen, Zu-guo, Lin-li Tian, and Xun Liu. 2019. "Automotive Exhaust Thermoelectric Generators : Current Status , Challenges and Future Prospects." Energy Conv. Manage. 195 (April): 1138-73.

Shu, Gequn, Xiaonan Ma, Hua Tian, Haoqi Yang, Tianyu Chen, and Xiaoya Li. 2018. "Configuration Optimization of the Segmented Modules in an Exhaust-Based Thermoelectric Generator for Engine Waste Heat Recovery." Energy. https://doi.org/10.1016/j.energy.2018.06.175.

Sornek, Krzysztof, Mariusz Filipowicz, and Kamila Rzepka. 2016. "The Development of a Thermoelectric Power Generator Dedicated to StoveFireplaces with Heat Accumulation Systems." Energy Conversion and Management. https://doi.org/10.1016/j.enconman.2016.05.091.

Su, C Q, M Xu, W S Wang, Y D Deng, X Liu, and Z B Tang. 2014. "Optimization of Cooling Unit Design for Automotive Exhaust-Based Thermoelectric Generators." J. Electronic Materials, 2-9.

Verma, Vishal, Aarti Kane, and Bhim Singh. 2016. "Complementary Performance Enhancement of PV Energy System through Thermoelectric Generation." Renew. Sustain. Energy Rev. 58: 1017-26.

Wang, Tongcai, Weiling Luan, Tongjun Liu, Shan-tung $\mathrm{Tu}$, and Jinyue Yan. 2016. "Performance Enhancement of Thermoelectric Waste Heat Recovery System by Using Metal Foam Inserts." Energy Con. Manage. 124: 13-19.

Wang, Wensi, Victor Cionca, Ningning Wang, Mike Hayes, Brendan O Flynn, and Cian O Mathuna. 2013. "Thermoelectric Energy Harvesting for Building Energy Management Wireless Sensor Networks." Inter. J. Distributed Sensor Networks https://doi.org/10.1155/2013/232438.

Wiriyasart, S, C Hommalee, R Prurapark, A Srichat, and P Naphon. 2019. "Case Studies in Thermal Engineering Thermal Efficiency Enhancement of Thermoelectric Module System for Cold-Hot Water Dispenser; Phase II." Case Studies in Thermal Engineering 15100520.

Zhang, Guobin, Linhao Fan, Zhiqiang Niu, Kui Jiao, Hai Diao, Qing Du, and Gequn Shu. 2015. "A Comprehensive Design Method for Segmented Thermoelectric Generator." Energy Con. Manage. 106: 510-19. 